\title{
An Evaluation of the Effectiveness of Simultaneous Ventriculo-Peritoneal Shunt Placement and the Sequential Shunting- in Neonatal Myelomeningocele
}

\author{
Md. Nowshad Ali ${ }^{1, ~}$, Mst. Rokeya Khatun ${ }^{2}$, Shah Md. Ahsan Shahid ${ }^{1}$, Md. Kamruzzaman ${ }^{3}$ \\ ${ }^{1}$ Department of Paediatric Surgery, Rajshahi Medical College, Rajshahi, Bangladesh \\ ${ }^{2}$ Department of Gynaecology and Obstetrics, Rajshahi Medical College, Rajshahi, Bangladesh \\ ${ }^{3}$ Department of Surgery, 250 Bed District Sadar Hospital, Feni, Bangladesh
}

Email address:

nowshadpedsur27@gmail.com (Md. N. Ali)

${ }^{*}$ Corresponding author

\section{To cite this article:}

Md. Nowshad Ali, Mst. Rokeya Khatun, Shah Md. Ahsan Shahid, Md. Kamruzzaman. An Evaluation of the Effectiveness of Simultaneous Ventriculo-Peritoneal Shunt Placement and the Sequential Shunting- in Neonatal Myelomeningocele. International Journal of Clinical and Experimental Medical Sciences. Vol. 6, No. 4, 2020, pp. 65-70. doi: 10.11648/j.ijcems.20200604.13

Received: February 5, 2020; Accepted: June 10, 2020; Published: August 4, 2020

\begin{abstract}
A randomized control trail study has been designed and carried out during the period of July 2014 to October 2016 (27 months) in the Department of Paediatric Surgery, Rajshahi Medical College, Rajshahi, Bangladesh. Twenty Six (26) neonates with myelomeningocele were taken as sample volume. This study was under taken to evaluate the effectiveness of simultaneous ventriculo-peritoneal shunt placement and the sequential shunting. These patients were randomly selected for this study and divided in to two groups. Thirteen patients were undergone repair of myelomeningocele with simultaneous insertion of vetriculo-pritoneal shunt and another 13 patients were undergone only myelomeningocele repair, at first stage. Twelve (12) patients were developed hydrocephalus later that subsequently needed ventriculoperitoneal shunt placement on an average after 31 days. Simultaneous surgery had the advantage of exposing the patients to one rather than two operations. Duration of hospital stay has reduced seven days, though operation time has increased 44 minutes that has not affected the outcome. No difference did exist between two groups but those were shunted simultaneously appeared to enjoy clear benefit. There was significant difference of wound complications like wound breakdown and wound infection between two groups, but wound leakage exclusively occured seven patients in sequentially shunted patients. Shunt related complications were remained same in both groups. There was gross deviation of preoperative OFC $(+5.15 \%)$ in sequentially shunted patients, which was improved after shunt placement $(+2.04 \%)$. But, there was significant $(\mathrm{P}<0.001)$ difference of OFC between two groups on follow up. Ventricular diameter was rapidly increased $(42.65 \mathrm{~mm})$ after repair of myelomeningocele in sequential shunted patients that was reduced after shunt placement but remained at least $7 \mathrm{~mm}$ larger than the simultaneous shunted patients. This has also affected the expansion of cortical thickness of brain in sequentially shunted patients which was $3 \mathrm{~mm}$ less than simultaneously shunted patients. This difference significantly $(\mathrm{P}<0.01)$ differ the intelligence quotient. Simultaneously shunted patients also enjoying better health (67\%) than sequentially shunted (56\%) patients. Simultaneous shunting avoided prolong periods of progressive hydrocephalus compared with those sequentially shunted, thereby averting further cerebral injury and improving intelligence and physical growth.
\end{abstract}

Keywords: Comparison, Simultaneous V-P Shunting, Sequential V-P Shunting

\section{Introduction}

Neural tube defect or spinal dysraphism is one of the common congenital malformation [1]. This disorder is due to incomplete closer of spinal arch at one or more level or disruption of an already formed neural tube between $18-28$ days of gestation [2]. The resulting abnormalities ranging from mild spina bifida oculta to severe spina bifida cystica with varying degree of lower limb paralysis and bowel and bladder control [3]. Spina bifida cystica constitute $95 \%$ of all 
neural tube defect. $5 \%$ of all neural tube resulting from spina bifida oculta usually not associated with neurological abnormalities. Though only $5-10 \%$ of myelomeningocele neonate have clinically overt hydrocephalous at birth while it eventually develops in $85-90 \%$ patient before the age of 6 months [4]. There is geographical variationof this defect in the world. Incidence varies from 0.5 (Finland) to 4.5 (Ireland) per 1000 live birth [5]. Low social group have a higher incidence of defect [6]. The exact mode of inheritance is not known but increased incidence with parental consanguinity and familial tendency suggest its multifactorial hereditary predisposition [7]. Though exact cause is unknown, some known factors such as maternal alcohol, maternal diabetics, $\mathrm{X}$-ray irradiation, amniotic band disruption and some maternal nutritional deprivation increase the incidence. Some suspected factors such as drugs like carbamazepine, valproate, maternal hyperthermia; exposer to rubella may be responsible for the neural tube defect [8,9]. Deficiency of folic acid and zinc in pregnancy is one of the known causes of the defect [10]. Incidence also increases in times of war, famine or economic disaster [11]. Diagnosis of myelomeningocele is obvious at birth. It can be diagnosed antenatally by combination of high-resolution ultrasonography, maternal serum alpha-fetoprotein and acetylcholinesterase estimation, has greatly improve the antenatal diagnosis hence improve obstetric care and conversely termination of pregnancy of affected fetus if desired [12, 13]. Management of myelomeningocele has stirred a great deal of medical, ethical and legal controversy over the past 3 decades. This management requires a team approach involving specialist like Neurosurgeon, Paediatric surgeon, Neurologist, Neonatologist, Urologist, Radiologist, Physiotherapist, Social worker, Psychologist, trained nursing stuff and most of all patient's family and society so as to enable the patient to live a meaningful life [14]. In the management of myelomeningocele, the patient without overt clinical hydrocephalus, most surgeons used to repair the myelomeningocele only [15]. But that result subsequent hydrocephalus in 65 to $85 \%$ within 6 months and also cause breakdown of repair and CSF leakage [16]. To prevent this complication some surgeons begins to do myelomeningocele repair and introduction of VP shunt at least 3 days after the initial repair [17]. This gives better result but increase hospital stays and imposes an additional operative trauma within a short interval. It also increases the incidences of wound complication [18]. In 1985, Epstein et al have shown significant improvement in the management of myelomeningocele by doing simultaneous placement of VP shunt during repair of myelomeningocele. This decreases hospital stay, prevent repair failure, prevent or delay the development of subsequent hydrocephalus [19]. Report from abroad on successful treatment of myelomeningocele, prompted to undertake this study to compare the outcome of simultaneous shunt placement and repair of myelomeningocele versus repair only and subsequent shunt placement, if needed.

\section{Objectives}

General Objective:

To compare the effectiveness of simultaneous and sequential V-P shunting in treatment of myelomeningocele in neonate.

Specific Objectives:

To measure the outcomes in terms of:

1. Wound complication.

2. Occipital-frontal circumference.

3. Ventricular size of brain.

4. Cortical thickness of brain.

5. Physical \& mental growth.

\section{Methodology and Materials}

This randomized control trail study has been designed and carried out during the period of July 2014 to October 2016 (27 months) in the Department of Paediatric Surgery, Rajshahi Medical College, Rajshahi, Bangladesh. 26 patients were taken as sample volume. These patients were devided in to two groups, Group-A included 13 patients who were underwent myelomeningocele repair and simultaneous insertion of ventriculo-peritoneal shunt and Group- B was also included 13 patients, who were underwent only myelomeningocele repair in the initial period. Though 12 $(92.30 \%)$ of Group - B were required shunt placement subsequently.

Inclusion criteria

Neonate admitted with myelomeningocele with ventricular diameter between 15-30 $\mathrm{mm}$.

Exclusion criteria

1. Neonate having myelomeningocele with clinically overt hydrocephalus (Ventricular diameter $>40 \mathrm{~mm}$ ).

2. Gross kyphosis or scoliosis.

3. Associated gross life threatening congenital malformation (cardiac disease, anorectal malformation, oesophasial atresia).

4. Myelomeningocele with meningitis.

5. Patient age more than 30 days.

\section{Results}

This prospective study was performed in the period of July 2014 to October 2016 in the Department of Paediatric Surgery, Rajshahi Medical College, Rajshahi, Bangladesh. Total 26 patients, who fulfilled all the inclusion criteria, were selected for clinical study. Out of 26 patients, the lession were, $11(42 \%)$ in thoracic-lumber $11(42 \%)$ in lumber, 2 $(7.7 \%)$ in lumbosacral and $2(7.7 \%)$ in sacral region. The distribution of lesion between two groups was identica (Table 1). The patients of group - A were undergoing, myelomeningocele repair and simultaneous insertion of V-P shunt, required additional 42 minutes than Group -B patients (Table 2), who were underwent only myelomeningocele repair. Twelve (12) patients of the group -B have undergone two stage procedures (five in same admission and 7 in two 
different admission) Average hospital stay of group -B patients was 8 days more than group - A patient (Table 3). They was followed up according to prtocol for 3 years. Out of 26 patients, wound complication occurred in both groups (Table 4). Wound leakages were mostly (62.5\%) occurred in Group B patients and wound infection \& wound breakdown has occurred equally in both groups (Table 5). In this series, among 26 patients, 25 patients were shunted. Shunt related complications were developed $53.8 \%$ in group-A and $46.2 \%$ in Group-B (Table 6). Four patients develop shunt infection; two patients developed peritonitis, one distal shunt obstruction, one patient developed right-sides communicating hydrocele and one patient developed intentional obstruction (Table 7). Complications were identical to both the groups. Cortical thickness was measured preoperative and postoperative by USG. The pre-operative average cortical thickness of Group-A was $27.23 \mathrm{~mm}$ and Group-B was 27.07 $\mathrm{mm}$. At the age of ninety days cortical thickness was increased to $33.00 \mathrm{~mm}$ in group-A and $29.07 \mathrm{~mm}$ in Group-B. Cortical thickness was significantly improved in both groups (group A 21.89\% and group B 7.38\%) but at 3 months age, there was significant $(\mathrm{P}<0.05)$ difference of cortical thickness between two groups (Table 8). All patients of Group A and
Group B were monthly followed up to measure intelligence quotient (IQ) in percentage. It was measured with the help of Bayley scale of infant development (BSID) by the child development center, Department of pediatrics of same institute. At the age of 3 months the average intelligence quotient (IQ) of Group- A was 100.15\% and Group- B was $66.54 \%$. Intelligence quotient was significantly $(\mathrm{P}<0.01)$ differing between two groups (Table 9). There was positive correlation between cortical thickness and intelligence quotient. Physical development was measured monthly in percentage (\%) by child development center of same institute. Mean physical growth at the age of 3 month of group-A patients was $74.15 \%$ and group -B patients were $51.54 \%$ (Table 10). Among 13 patients, twelve patients needed second operation (V-P shunt insertion). Five of them developed continuous leakage of CSF through repair wound post operatively,. When it persists for more than five days, V$\mathrm{P}$ shunting was done in same admission. Other 7 patients needed shunting on separate admission on an averages interval of 35 days due to progressive ventriculomegaly. Average interval of shunt insertion of all 12 patients was 24 days (Range 10-45 days) following repair of myelomeningocele (Figure 1).

Table 1. Location of lesion. $(n=26)$.

\begin{tabular}{llllll}
\hline Site & Group A & \% & Group & \% & P value \\
\hline Thoracolumbar & 6 & 46.2 & 5 & 38.5 & \\
Lumbar & 5 & 38.5 & 6 & 46.2 & $>0.50 \mathrm{~ns}$ \\
Lumbosacral & 1 & 7.7 & 1 & 7.7 & \\
Sacral & 1 & 7.7 & 1 & 7.7 & \\
\hline
\end{tabular}

Table 2. Duration of time of the operation among study participants. $(n=26)$.

\begin{tabular}{llll}
\hline Duration of operation (minutes) & Group A & Group B & P value \\
\hline Means & $61.61 \pm 12.40$ & $39.46 \pm 3.31$ & $>0.50 \mathrm{~ns}$ \\
Range & $50-72$ & $30-52$ & \\
\hline
\end{tabular}

Table 3. Duration of hospital stay among study participants. $(n=26)$.

\begin{tabular}{llll}
\hline Hospital stay (days) & Group A & Group B & P value \\
\hline Means & $18.76 \pm 7.89$ & $26.23 \pm 8.11$ & $>0.50 \mathrm{~ns}$ \\
Range & $12-29$ & $15-37$ & \\
\hline
\end{tabular}

Table 4. Wound related complications at the site of myelomeningocele repair ( $n=26)$.

\begin{tabular}{llllll}
\hline Shunt related complications & Group A & \% & Group B & \% & P value \\
\hline Yes & 7 & 53.8 & 8 & 61.5 & $>0.50 \mathrm{~ns}$ \\
No & 6 & 46.2 & 5 & 38.5 & \\
\hline
\end{tabular}

Table 5. Types of wound related complications at the site of myelomeningocele repair $(n=26)$.

\begin{tabular}{lllll}
\hline Types of complication & Group A & \% & Group B & \% \\
\hline Wound breakdown & 6 & 85.7 & 4 & 50.0 \\
Wound leakage & 0 & & 5 & 62.5 \\
Wound infection & 3 & 42.9 & 6 & 75.0 \\
\hline
\end{tabular}

Table 6. Shunt related complications $(n=26)$.

\begin{tabular}{llllll}
\hline Shunt related complications & Group A & \% & Group B & \% & P value \\
\hline Yes & 7 & 53.8 & 6 & 46.2 & 7 \\
No & 6 & 46.2 & $70.50 \mathrm{~ns}$ & 53.8 & 7 \\
\hline
\end{tabular}


Table 7. Types Shunt related complications. $(n=26)$.

\begin{tabular}{|c|c|c|c|c|}
\hline Types of & Group A & $\%$ & Group B & $\%$ \\
\hline Shunt infection & 2 & 28.56 & 2 & 28.56 \\
\hline Peritonitis & 1 & 14.28 & 1 & 14.28 \\
\hline Shunt obstruction & 1 & 14.28 & 1 & 14.28 \\
\hline Rt. Sided hydrocele & 1 & 14.28 & 1 & 14.28 \\
\hline Intestinal & 1 & 14.28 & 1 & 14.28 \\
\hline Obstruction & 1 & 14.28 & 0 & 0 \\
\hline
\end{tabular}

Table 8. Preoperative and postoperative cortical thickness of the two study groups. $(n=26)$.

\begin{tabular}{llll}
\hline Groups & Cortical thickness. (mm) preoperative (Means) & preoperative (at 90 days' age) (Means) & Percent (\%) rise \\
\hline Groups A $(\mathrm{n}=13)$ & $27.23 \pm 3.18$ & $33.00 \pm 2.89$ & 21.89 \\
Groups B $(\mathrm{n}=13)$ & $27.07 \pm 3.23$ & $29.07 \pm 3.88$ & 7.38 \\
P value & & & $<0.05$ \\
\hline
\end{tabular}

Table 9. Intelligence quotient of the two study groups at the age of 3 months'. (n=26).

\begin{tabular}{llll}
\hline IQ & Group A & Group B & P value \\
\hline Means & $100.15 \pm 6.95$ & $66.54 \pm 9.38$ & $<0.001$ \\
Range & $68-110$ & $52-100$ & \\
\hline
\end{tabular}

Table 10. Physical development in the two study groups at age of 3 month $(n=26)$.

\begin{tabular}{llll}
\hline Physical development (\%) & Group A & Group B & P value \\
\hline Means & $74.15 \pm 17.55$ & $51.54 \pm 13.89$ \\
Range & $58-95$ & $42-90$ & $<0.01$ \\
\hline
\end{tabular}

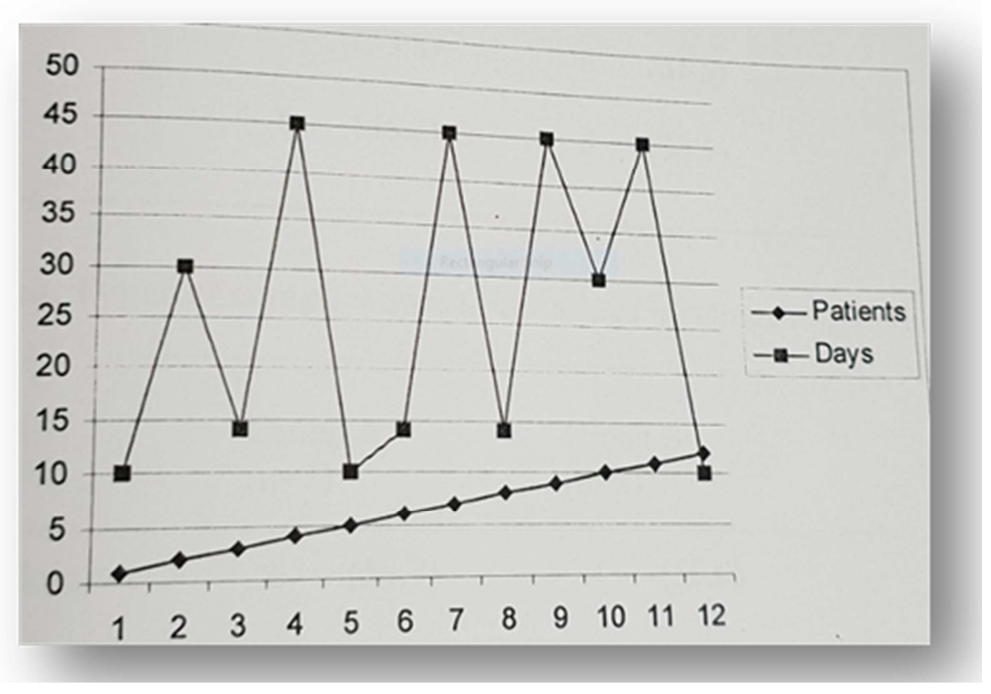

Figure 1. Interval of V-P Shunting after repair of myelomeningocele.

\section{Discussion}

The spinal dysraphism is not only a problem of developed country but also emerging as an alarming problem in developing country like Bangladesh. There is constant review and research to develop an optimal plan of management of patients with myelomeningocele and hydrocephalus. With this view, this randomized control trail study has been designed and carried out during the period of July 2014 to October 2016 (27 months) in the Department of Paediatric Surgery, Rajshahi Medical College Hospital, Bangladesh. 26 patients were taken as sample volume. These patients were grouped in to two groups, Group-A included 13 patients who were underwent myelomeningocele repair and simultaneous insertion of ventriculo-peritoneal shunt and Group- B was also included 13 patients were underwent only myelomeningocele repair in the initial period. Though 12 $(92.30 \%)$ of them were required shunt placement subsequently. All the patients of this series were neonate, age ranging 1 day to 21 days with an average 7.38 days in Group$A$ and 7.15 days in Group- B. There was no significant difference $(\mathrm{P}>0.5)$ of age between two groups. This delay in hospital reach is due to absence of antenatal diagnosis, illiteracy and limitation of neonatal care facilities. Averages hospital stay of Group- A patient was 23.62 days (range 12 days to 39 days) and Group-B has 30.15 days (range 17 days to 47 days). There was significant $(\mathrm{P}<0.5)$ increase in hospital stay in Group-B patients. Although simultaneous shunting has shortened the hospital stay, overall hospital stay 
of both groups were long. It corresponds with other study [19]. This is not only due to Medical cause but other social factors are also responsible for it. Mean operation time of Group -A patient was 81.38 minutes which was 44 minutes longer then Group B patients, that corresponds with the study of Hubballah and Hoffman [17] but this has not affect the outcome instead of avoiding the second operation that has needed $12(92.30 \%)$ patients of Group -B. 12, out of 13 of Group- B, hydrocephalus was sonographycally confirmed within average 17 days after myelomeningocele repair and by the $31^{\text {st }}$ day most shunt were in place with a range of 12 to 46 days. The delay in shunt placement has affected the outcome as describe by Epstein et al [19], they have detected Hydrocephalus as early as 4 days and most of the shunting completed within 12 days. There was no significant $(\mathrm{P}>0.5)$ difference of wound complication between the groups. The frequencies of wound breakdown were same in each (GroupA, 6 \& Group- B, 7). None developed CSF leakage is Group A whereas 7 of sequentially shunted patient experienced wound leakage, at an average 6 days after myelomeningocele repair and that was stopped at average 5 days after shunt placement. This corresponds with the study of Hoffman [20]. Wound infection developed in 5 patients of Group -A with wound breakdown, which was adequately treated with intravenous antibiotic alone and no surgical intervention was required. On the other hand, 3 of sequentially shunted patients were developed wound infection that required additional operative debridement. The incidence of wound infection was higher than the study of Hubballah and Hoffman [17], they have no wound infection probably it was due to that they have done the repair within 24 hour of birth, before colonization of bacteria at the skin [21]. Shunt related complications between two groups were also insignificant. Patient undergoing simultaneous shunting, 2 patients were developed right sided hydrocele (due to shunting at early age) and one developed intestinal obstruction, other than that the incidence of shunt malfunction and shunt infection was equal in both groups, all were improved by conservative measure, none require revision shunting, which correlate with the study of Epstein et al [19]. There was $3.22 \%$ positive deviation of occipitofrontal circumference preoperatively in group-A patient that has reduce to $0.76 \%, 90$ days after operation, but in case of Group-B it was $5.15 \%$ before operation and $2.04 \%$ after operation. There was significant difference of OFC between two groups in both pre and postoperatively. Mean postoperative OFC of group-A patients were $40.65 \mathrm{~mm}$ and Group-B patients were $41.21 \mathrm{~mm}$ that indicate significant improvement of OFC in simultaneously shunted patients. This improvement correlate with the study of Russel et al [18], though they mention that head circumference at birth is a poor predictor of hydrocephalus [18]. In this series there was significant diminution of ventricular size after V-P shunt placement. In Group-A patients mean preoperative ventricular diameter were $28.46 \mathrm{~mm}$ (range $22 \mathrm{~mm}-30 \mathrm{~mm}$ ) and mean postoperative ventricular diameter were $22.23 \mathrm{~mm}$ (range $18 \mathrm{~mm}-30 \mathrm{~mm}$ ). 90 days after operation the mean reduction of ventricular size was $6.23 \mathrm{~mm}$. In Group $-\mathrm{B}$ the preoperative mean ventricular diameter was $42.62 \mathrm{~mm}$ and postoperative mean ventricular diameter was $35 \mathrm{~mm}$ with an average reduction of $7 \mathrm{~mm}$. There was significant difference of pre and post-operative ventricular size between two groups and also significant reduction of ventricular size in both groups, that implied better outcome if shunting done simultaneously. This result concise with the study of Harold [22]. Mean difference of pre shunting $(26.12 \mathrm{~mm})$ and post shunting $(33.77 \mathrm{~mm})$ cortical thickness in-group -A patients were $7.65 \mathrm{~mm}$ and Group-B patients were $5.15 \mathrm{~mm}$. Cortical thickness expansion of Group-B patients were lower than Group-A. That implied significant $(\mathrm{P}<0.05)$ improvement of cortical thickness if shunting done simultaneously. This is in keeping with the findings of Lorber \& Salfield [4]. Improvement in IQ (intelligence quotient) was also more in Group -A (mean -106.62\%) than Group -B (mean -94.69\%). There was significant difference $(\mathrm{P}<0.01)$ of I/Q between two groups, which correlate with the previous study Timothy et al [23]. In this series, there was positive correlation between postoperative cortical thickness and I/Q. The improvement of physical development is more in Group -A (mean 67.38\%) than Group -B (mean 56.23\%). The patients of group-A were significantly $(\mathrm{P}<0.05)$ enjoying better health than group- $\mathrm{B}$.

\section{Limitations of The Study}

We conducted this study in one Centre with limited sample size. So, study result can't reflect the scenarios of the whole country. Case-control study can identify the risk factors more accurately.

\section{Conclusion and Recommendations}

This study was under taken to evaluate the effectiveness of simultaneous ventriculo-peritoneal shunt placement and the sequential shunting. Infant born with myelomeningocele and hydrocephalus should undergo simultaneous shunting and repair of the myelomeningocele if hydrocephalus can be shown by sonography in the immediate perinatal period. There appears to be no associated increase in morbidity or mortality and the benefits are substantial.

\section{References}

[1] Leven, M 1995, 'Spectrum of neural tube deffects', in Fetal and neonatal neurology and neurosurgery, 2nd edn, Leven, MI, Lilford, RJ, Churchill livingstone, Newyork, 16, pp. 218221.

[2] Warwick, JP, 1998, 'Management of spina bifida, Hydrocephalus, central nervous system infections and intractable epilepsy', in Paediatric surgery, 5th edn, O'Neill, Row, Grosfield, Mosby-year book, Missuri, 21, pp. 1849-1853.

[3] Reigel, DH, \& Rotenstein, D 1994, 'Spina bifida' in Pediatric Neurosurgery, $3^{\text {rd }}$ edn, Check, WR, Marlin, AE, McLone, DG, Warker, MZ, WB sanders company, Philadlphia, London, 3, pp. 51-53. 
[4] Lorber, J \& Salfield, S 1981, 'Result of selective treatment of spina bifida cystica', Arch Dis Child, 56, pp. 822-826.

[5] Leek, I, 1984 'The geographic distribution of neural tube deffect and oral cleft', Br. Med. Bull, 40, pp. 390-395.

[6] Leek, I 1972, ' The aetiology of human malformation and insights from epidemiology', teratology, 5, pp. 300-303.

[7] Carter, CO 1975, 'Clues to the aetiology of Neural tube malformation', Develop Med s Child Neurol, 16 (32), pp. 3-15.

[8] Milunsky, A, Uleickas, M, Rothman, J 1992, 'Maternal heat exposer and neural tube defects', Journal of American Medical Association, 268, pp. 882-885.

[9] Oakeshott, P \& Hunt, GM 1989, 'valproate and spina bifida', British Medical Journal, 298, pp. 1300-1301.

[10] Mulenare, J, Cordero, JF, Erickson, JD, Berry, RJ 1988, 'Periconceptional use of multivitamins and the occurrence of neural tube defects', Journal of American Medical Association, 260, pp. 3141-3145.

[11] Lorber, J \& Ward, AM 1985, 'Spina bifida-A vanishing nightmare?' Arch Dis, Child, 60, pp. 1086-1091.

[12] Mouric, MC, Conner, JM, Ferguson Smith, MA 1990, 'Patient care befoe and after termination of pregnancy for neural tube deffects', Prenatal Diag, 10 (8), pp. 497-505.

[13] Neven, P, Ricketts, NEM, Gerisson, RT, Smith, R, Crawford, JW 1991, 'Screning for neural tube defect with maternal serum alpha feto protein and ultrasound without the use of amniocentesis', Journal of obstetics and Gynaecology, 11, pp. $5-8$.

[14] Puri, P and Sharma, R 2003, 'Spina bifida and Encephalocele', in Newborn surgery, 2nd edn, Prempuri, Arnold, London, 82, pp. 761-765.
[15] McLone, DG \& Naidich, TP, 1995, 'The investigation of hydrocephalus by computed tomography', Clin Neurosurg, 32, pp. 527-529.

[16] Steinbok, P, Brendon Irvin, D. Douglus Cochrane and Beverly, J, Irwin 1992, 'Long term outcome and complication of children born with myelomeningocele', Child's Nerv Syst, 8, pp. 92-96.

[17] Hubballah, MY \& Hoffman, HJ 1987, 'Early repair of myelomeningocrlr and simultaneous insertion of VP shunt: Trchnique and Result', J Neurosurgery, 20, pp. 21-23.

[18] Russell, RCG, Williams, NS, Bulstrode, CJK (eds) 2004, 'Elective Neurosurgery', in Baily \& Love's Short Practice of Surgery, $24^{\text {th }}$ edn, Arnold, London, ISE in Oxford University Press Inc, New york, 44, pp. 606-615.

[19] Epstein, NE, Rosenthal, AD, Joshep, Z, Osipoff, M 1985, 'Shunt placement and myelomeningocele repair: simultaneous VS sequential shunting, Review of 12 cases', Child's Nerv Syst, 1, pp. 145-147.

[20] Hoffman, HJ, 1997, 'Myelomeningocele, Curent therapy in Neurological surgery', concept paediatric Neuro Surg, 12, pp. 217-223.

[21] McLone, DG \& Naidich, TP 1989, 'Myelomeningocele: Outcome and late complication, In Paediatric Neurosurgery, 2nd edn, Mc Lanria, RL, Schent, L, Venes, JL, Philadelphia, WB Saunders, 12, pp. 53-70.

[22] Harold, LR 1984, 'To shunt or not to shunt: Hydrocephalus and Dysraphism', Concept of Pediatric Neurosurg, 29, pp 593607.

[23] Timothy, BM, Harold, LR, Nulsen, FE, Dixon, MS, Glaser, N, Miriam, J 1984, 'Relationship of CSF shunting and IQ in children with myelomeningocele: A retrospective analysis' Child Brain, 11, pp. 112-118. 